\title{
Approximate Mathematical Modeling of Osmotic Dehydration of Cone- Shaped Fruits and Vegetables in Hypertonic Solutions
}

\author{
Mohammad Sirousazar* \\ Faculty of Chemical Engineering, Urmia University of Technology, P.O. Box 57155-419, Urmia, Iran \\ A R T I C LE INFO \\ A B S T R A C T \\ Research Article \\ Received 04 June 2016 \\ Accepted 28 June 2017 \\ Keywords: \\ Osmotic dehydration \\ Mass transfer \\ Mathematical modeling \\ Cone-shaped fruit \\ *Corresponding Author: \\ Water loss kinetics in osmotic dehydration of cone-shaped fruits and vegetables was \\ modeled on the basis of diffusion mechanism, using the Fick's second law. The model \\ was developed by taking into account the influences of the fruit geometrical \\ characteristics, initial water content of fruit, water diffusion coefficient in fruit, and the \\ water concentration in hypertonic solution. Based on the obtained model, it was shown \\ that the water diffusion coefficient and the initial water concentration of fruit have direct \\ effects on the dehydration rate and also inverse influence on the dehydration duration. \\ The geometrical parameters of fruit and water concentration in hypertonic solution \\ showed direct effect on the dehydration duration as well as inverse effect on the \\ dehydration rate. The presented model seems to be useful tool to predict the dehydration \\ kinetics of cone-shaped fruit during osmotic dehydration process and to optimize the \\ process prior to perform the experiments.
}

E-mail: m.sirousazar@uut.ac.ir

DOI: https://doi.org/10.24925/turjaf.v5i6.581-585.821

\section{Introduction}

Osmotic dehydration is widely used to remove part of the water content of fruit without structure damages to obtain a product containing intermediate moisture with reduced water activity (Segu et al., 2006; Garcia-Segovia et al., 2010). It is a water removal process, which is based on immersing fruits or legumes in a hypertonic or osmotic solution, i.e. concentrated aqueous solution of soluble solids such as sugar, salt, sorbitol, and glycerol having higher osmotic pressure and lower water activity (Ohnishio and Miyawaki, 2005; Chenlo et al., 2006; Kaymak-Ertekin and Sultanoglu, 2000; Vega-Mercado et al., 2001).

The use of osmotic dehydration in the food industry has several advantages in comparison to conventional dehydration processes, e.g. quality improvement in terms of color, flavor and texture, energy efficiency, packaging and distribution cost reduction, no chemical pretreatment, product stability, and retention of nutrients during storage (Bui et al., 2009). The rate of dehydration (water loss) during the osmotic dehydration depends upon factors such as: solution concentration, immersion time, solution temperature, size and geometry of the fruit, solution to fruit mass ratio and level of agitation or circulation of the hypertonic solution. A large number of recent publications have described both mathematically and experimentally the influence of these variables on dehydration kinetics and mass transfer rates during osmotic dehydration (Pisalkar et al., 2014; Sutar and
Gupta, 2007; Moreira et al., 2007; Silva et al., 2014; Ispir et al., 2009; Alam and Singh, 2010; Zita et al., 2009; Simpson et al., 2015). Mass transfer modeling of osmotic dehydration is necessary for understanding the process as well as to develop design and control schemes. However, the complex structure of the fruit and the multiple processes involved during mass transfer between the fruit and the hypertonic solution makes the modeling of osmotic dehydration complex (Bui et al., 2009).

Fick's second law is usually applied to find an approximate solution, and the effective diffusivity of water in the tissue is used to account for the variation of the physical properties of the tissue as well as for the influence of the hypertonic solution characteristics and process variables (Kaymak-Ertekin and Sultanoglu, 2000; Segu et al., 2006; Garcia et al., 2007; Sirousazar et al., 2009; Bui et al., 2009). In the models based on the Fick's second law, the diffusion of water from the inside of the fruit to the surrounding hypertonic solution plays the major role in the osmotic dehydration. In this case, the concentration gradient of water between the inside and outside of the fruit acts as the driving force for the mass transfer of water and the rate of moisture loss (Sirousazar et al., 2009). Much work has been performed in developing mathematical models to predict the mass transfer kinetics of the osmotic dehydration process for the fruits having the simple geometric configurations, i.e. slab, cylinder and sphere (Sutar and Gupta, 2007; 
Sirousazar et al., 2009). Nonetheless, the lack of mathematical models is evident for predicting the osmotic dehydration of the other kinds of fruits having complicated shapes, such as cone-shaped fruits and vegetables (e.g. strawberries, carrot and pepper).

The objective of this work is to model the water loss during the osmotic dehydration of cone-shaped fruits. The model is developed on the basis of Fick's law by taking into account the influences of the geometrical characteristics and physical properties of the fruit, and the properties of the hypertonic solution.

\section{Mathematical Modeling}

Figure 1 shows a schematic two-dimensional view of a typical cone-shaped fruit with base radius of $a$ and height of $b$. In order to study the dehydration kinetics of this fruit on the basis of the diffusion model, we should analyze the Fick's second law in cylindrical coordinates.

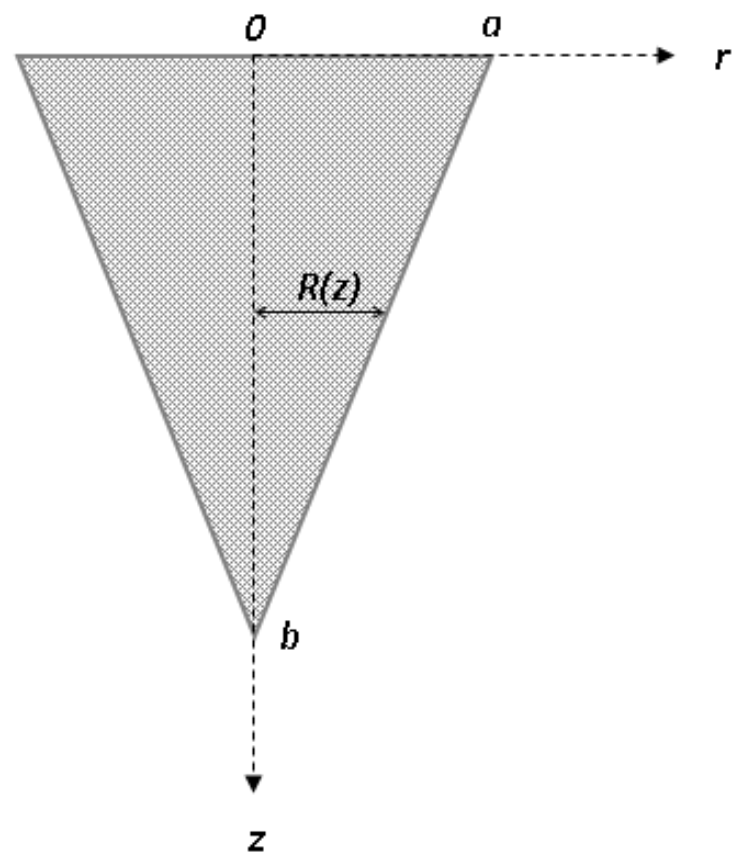

Figure 1 The geometrical dimensions of a typical coneshaped fruit.

The below assumptions were used in the mathematical modeling:

- The water diffusion from fruit into hypertonic solution is the dehydration rate controlling step rather than other phenomena such as tissue swelling.

- The ratio of height to base radius of fruit is so high (b>>a), so the diffusion of water is assumed to be one dimensional, i.e. it occurs in $r$ direction.

- The water diffusion coefficient in fruit tissue $(D)$ is constant and independent of concentration.

- The concentration of water in hypertonic solution $(C$ $e$ ) is constant, during the dehydration process (the hypertonic solution is assumed as an infinite source).

- The initial concentration of water in fruit is $C_{0}$.
In this case, the concentration of water inside the fruit $(0 \leq r \leq a$ and $0 \leq z \leq b)$ as a function of $r$ and $t$ can be determined by transient diffusion based on the Fick's second law for the cylindrical coordinates:

$$
\frac{\partial C}{\partial t}=D\left(\frac{\partial^{2} C}{\partial r^{2}}+\frac{1}{r}+\frac{\partial C}{\partial r}\right)
$$

The initial and boundary conditions governing this system are:

$$
\begin{aligned}
& C(r, 0)=C_{0} \\
& C(R(z), t)=C_{e} \\
& C(0, t)=\text { finite }
\end{aligned}
$$

Where, $R(z)$ is the radius of fruit at the height of $z$. The Eqs. 2 and 3 were written based on our assumptions and the Eq.4 is right because we know that the concentration of water in the center of fruit $(r=0)$ is not infinite and has a finite value.

The Eqs.1-4 is a partial differential equation with nonhomogenous boundary conditions which could be converted to a problem with homogenous boundary conditions by defining a new function $(r, t)$, as follows:

$$
U(r, t)=C(r, t)-C_{e}
$$

Using the Eq.5, the Eqs.1-4 will found new forms in term of $U(r, t)$ :

$$
\begin{aligned}
& \frac{\partial U}{\partial t}=D\left(\frac{\partial^{2} U}{\partial r^{2}}+\frac{1}{r}+\frac{\partial U}{\partial r}\right) \\
& U(r, 0)=C_{0}-C_{e} \\
& U(R(z), t)=0 \\
& U(0, t)=\text { finite }
\end{aligned}
$$

The above initial and boundary conditions problem (Eqs.6-9) can be solved on the basis of the method of separation of variables. The final solution of the Eq.6 using the boundary conditions (Eqs.8 and 9) is:

$$
U(r, t)=\sum_{n=0}^{\infty} F_{n} J_{0}\left(\frac{\alpha_{n} r}{R(z)}\right) \exp \left(\frac{-D \alpha_{n}^{2}}{(R(z))^{2}}\right) t
$$

Where, $F_{n}$ are constants, $J$ is the Bessel function of first kind and $\alpha_{n}$ are the roots of below equation:

$$
J_{0}\left(\alpha_{n}\right)=0, n=0,1,2,3, \ldots .
$$

Applying the initial condition (Eq.7) in Eq.10, gives the constants $F_{n}$ as:

$$
F_{n}=\frac{2\left(C_{0}-C_{e}\right)}{(R(z))^{2} J_{1}^{2}\left(\alpha_{n}\right)} \int_{0}^{R(z)} r J_{0}\left(\frac{\alpha_{n} r}{R(z)}\right) d r
$$


In order to withdraw the effect of the position variable $z$ on the model (as one of the modeling assumptions) and also to calculate the integral in Eq.12, an average value for $R(z)$ is considered in domain $0 \leq z \leq b$ as follows:

$$
\bar{R}=\frac{\int_{0}^{b} R(z) d z}{b}
$$

$R(z)$ could be replaced by:

$$
R(z)=a z / b
$$

Inserting Eq.14 in Eq.13 and integrating yields the $\bar{R}$ as:

$$
\bar{R}=a / 2
$$

Inserting Eq.15 in Eq.12, after integrating and mathematical simplifications gives the values of $F_{n}$ as:

$$
F_{n}=\frac{2\left(C_{0}-C_{e}\right.}{\alpha_{n} J_{1}\left(\alpha_{n}\right)}
$$

Finally, putting Eq.16 in Eq.10 and using Eq.5, the water concentration function inside the fruit (i.e. $C(r, t))$ will be obtained as:

$C(r, t)=C_{e}+2\left(C_{0}-C_{e}\right) \sum_{n=1}^{\infty} \frac{J_{0}\left(\frac{2 \alpha_{n} r}{a}\right)}{\alpha_{n} J_{1}\left(\alpha_{n}\right)} \exp \left(\frac{-4 D \alpha_{n}^{2}}{a^{2}} t\right)$

The rate of water diffusion from the fruit $(J)$ is given by the Fick's First law:

$$
J=-S D\left[\frac{\partial C(\bar{R}, t)}{\partial r}\right]
$$

Where, $\mathrm{S}$ is the surface area of the cone:

$$
S=\pi a \sqrt{\left(a^{2}+b^{2}\right)}
$$

The cumulative amount of removed water from fruit at time $t\left(M_{t}\right)$ could be determined by the below equation:

$$
M_{t}=\int_{0}^{t} J S d t
$$

Using the Eqs.17-20, $M_{t}$ is achieved as:

$$
M_{t}=\pi a^{2} \sqrt{\left(a^{2}+b^{2}\right)\left(C_{0}-C_{e}\right)} \sum_{n=1}^{\infty} \frac{1}{\alpha_{n}^{2}}\left[1-\exp \left(\frac{-4 D \alpha_{n}^{2}}{a^{2}} t\right)\right](\text { Eq. 21) }
$$

The total initial amount of water $\left(M_{\infty}\right)$ inside the fruit is expressed as:

$$
M_{\infty}=C_{0}\left(\frac{\pi a^{2} b}{3}\right)
$$

Finally, the fractional remove of water from fruit to the hypertonic solution at time $t$ can be obtained by dividing Eq. 21 to Eq.22:

$$
\frac{M_{t}}{M_{\infty}}=\frac{3 \sqrt{\left(a^{2}+b^{2}\right)\left(C_{0}-C_{e}\right)}}{b C_{0}} \sum_{n=1}^{\infty} \frac{1}{\alpha_{n}^{2}}\left[1-\exp \left(\frac{-4 D \alpha_{n}^{2}}{a^{2}} t\right)\right]
$$

\section{Results and Discussion}

Based on the developed mathematical model (Eq.23) the water loss rate and dehydration kinetics of the coneshaped fruits during the osmotic dehydration could be predicted. The osmotic dehydration curves $\left(M_{t} / M_{\infty}\right.$ versus $t$ ) were plotted by considering the effects of fruit geometrical characteristics as well as operating conditions including the base radius and height of fruit, water diffusion coefficient in fruit, initial water concentration in fruit, and water concentration in hypertonic solution.

Figure 2 demonstrates the effect of the base radius of cone-shaped fruits on the osmotic dehydration kinetics. The curves were plotted at constant values of $b=35 \mathrm{~mm}$, $D=10^{-9} \mathrm{~m}^{2} / \mathrm{s}, C_{0}=45 \mathrm{kmol} / \mathrm{m}^{3}$ and $C_{e}=20 \mathrm{kmol} / \mathrm{m}^{3}$ for a cone-shaped fruit with various base radius between 5-25 $\mathrm{mm}$. As seen, the presented model shows that a coneshaped fruit having smaller base radius exhibits higher value of $M_{t} / M_{\infty}$ at any arbitrary time of dehydration in comparison with the thicker one. In other words, it implies that the fruits with smaller base radiuses will be dried more rapidly than thicker ones. For instance, the fruit with $a=25 \mathrm{~mm}$ reaches to dehydration level of $M_{t} / M_{\infty}=0.25$ nearly in $3 \mathrm{~h}$, while this duration for the fruit having the base radius of $10 \mathrm{~mm}$ is about $50 \mathrm{~min}$.

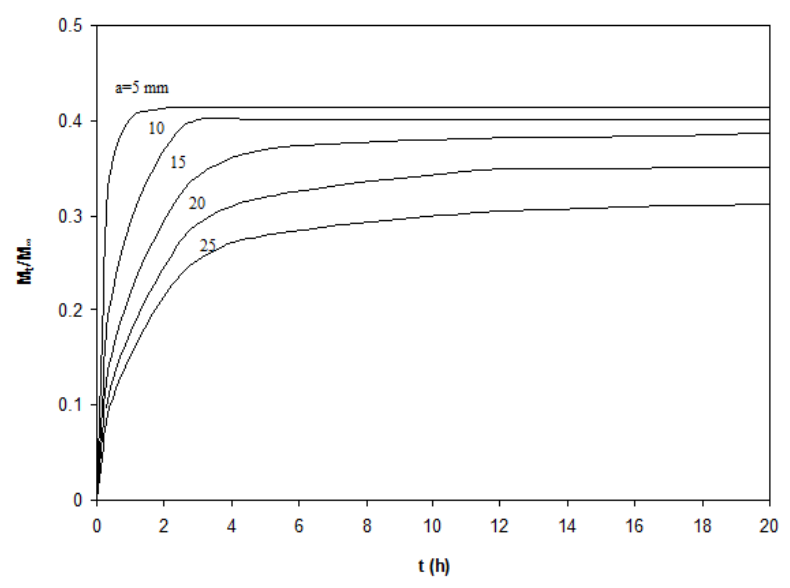

Figure 2 The effect of base radius of cone-shaped fruits on osmotic dehydration kinetics

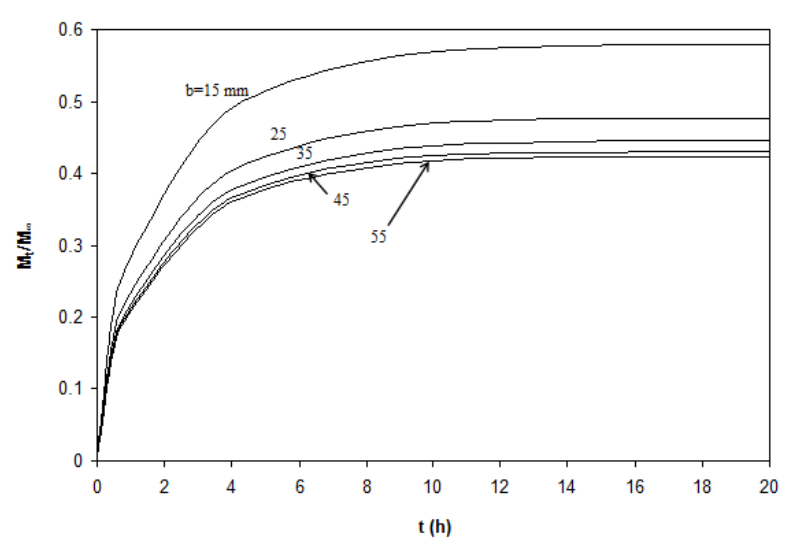

Figure 3 The effect of height of cone-shaped fruits on osmotic dehydration rate 


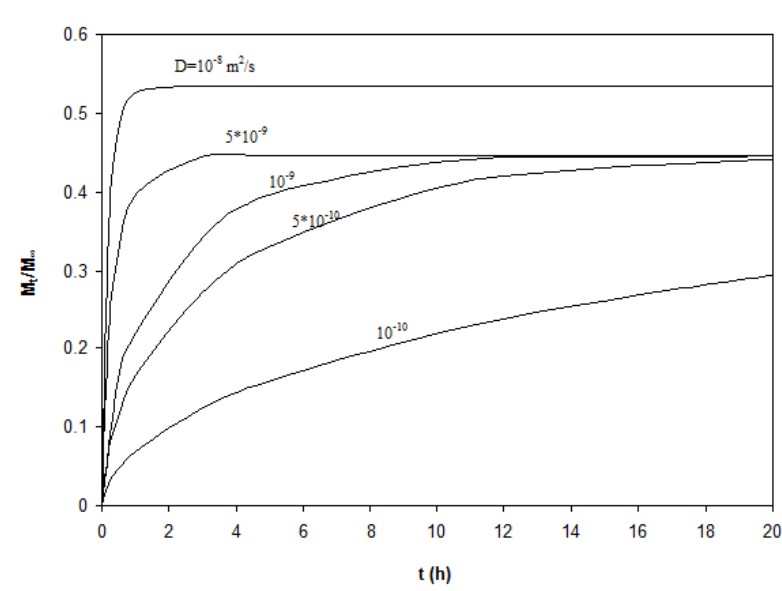

Figure 4 Osmotic dehydration curves of a cone-shaped fruit at different values of $\mathrm{D}$

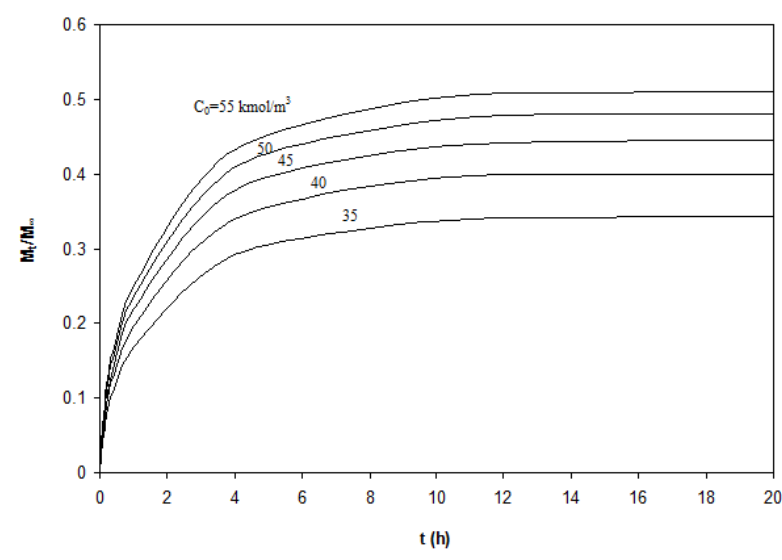

Figure 5 Dehydration kinetics of a cone-shaped fruit with different initial water content

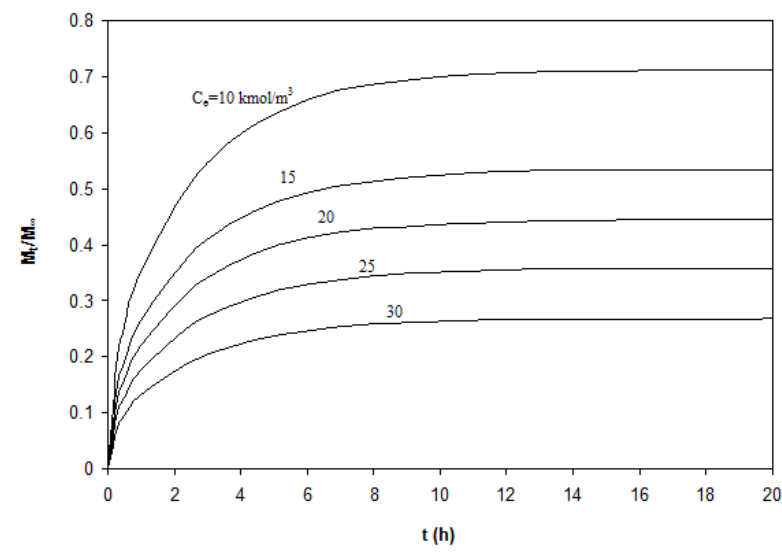

Figure 6 The effect of the water concentration in hypertonic solution on the osmotic dehydration of coneshaped fruits

The influence of another geometrical characteristic of cone-shaped fruits (i.e. $b$ ) on the osmotic dehydration process has been exhibited in Figure 3. The curves in Figure 3 were plotted using constant values for parameters, i.e. $a=15 \mathrm{~mm}, D=10^{-9} \mathrm{~m}^{2} / \mathrm{s}, C_{0}=45 \mathrm{kmol} / \mathrm{m}^{3}$ and $C_{e}=20 \mathrm{kmol} / \mathrm{m}^{3}$. A similar dehydration trend like the base radius (Figure 3) is observed for $b$. As can be seen, the height of the cone-shaped fruit has inverse effect on its dehydration kinetics. The fraction of water removed from a cone-shaped fruit having height of $35 \mathrm{~mm}$ after $5 \mathrm{~h}$ of initiating the osmotic dehydration process is 0.39 while, this value for the same fruit with height of $15 \mathrm{~mm}$ at the identical conditions as well as the same duration is 0.51 .

Figure 4 shows the effect of the water diffusion coefficient on the dehydration kinetics of a cone-shaped fruit having the radius of $15 \mathrm{~mm}$, the height of $35 \mathrm{~mm}$ and initial water concentration of $45 \mathrm{kmol} / \mathrm{m}^{3}$ in a hypertonic solution with water concentration of $20 \mathrm{kmol} / \mathrm{m}^{3}$. It can be seen that the fraction of water removed the fruit has strong dependency to the diffusion coefficient, in a manner which increasing the value of $D$ (which can be achieved by increasing the temperature of process), causes the fruit to reach to the higher equilibrium levels in a shorter period. On the other hand, Figure 4 reveals that the water migration in the more permeable fruits (fruit having higher value of $D$ ) occurs faster that those with lower permeability.

The effect of the initial water content of cone-shaped fruits on osmotic dehydration rates was investigated on the basis of presented model and shown in Figure 5. The curves in Figure 5 were plotted using constant values for parameters, i.e. $a=15 \mathrm{~mm}, b=35 \mathrm{~mm}, D=10^{-9} \mathrm{~m}^{2} / \mathrm{s}$ and $C_{e}=20 \mathrm{kmol} / \mathrm{m}^{3}$. A direct relationship between the time required reaching to a specified level of dehydration and the initial water concentration of fruit is observed. This could be attributed to the higher driving force for mass transfer (higher water concentration gradient between fruit and hypertonic solution) in fruits with higher initial water content.

Figure 6 exhibits the osmotic dehydration curves of a cone-shaped fruit with radius of $15 \mathrm{~mm}$, height of $35 \mathrm{~mm}$, initial water concentration of $45 \mathrm{kmol} / \mathrm{m}^{3}$ and water diffusion coefficient of $10^{-9} \mathrm{~m}^{2} / \mathrm{s}$ in different hypertonic solutions with water concentration of $10,15,20,25$, and $30 \mathrm{kmol} / \mathrm{m}^{3}$. As seen in Figure 6, the presented model shows that the water concentration in hypertonic solution has drastic effect on the osmotic dehydration of coneshaped fruits. The fraction of water removed from fruit at a specified time is increased by decreasing the water concentration in hypertonic solution (i.e. by concentrating the solution). For instance, the aforementioned coneshaped fruit reaches to a dehydration level of $M_{t} / M_{\infty}=0.66$ in $6 \mathrm{~h}$ using a hypertonic solution with water concentration of $25 \mathrm{kmol} / \mathrm{m}^{3}$, while this level is reduced to half in the same duration, if we use another hypertonic solution with water concentration of $10 \mathrm{kmol} / \mathrm{m}^{3}$.

\section{Conclusion}

In this work, a mathematical model on the basis of diffusion mechanism was presented to predict the osmotic dehydration of cone-shaped fruits and vegetables in hypertonic solutions. The model gives the fractional removal of water from fruit to the hypertonic solution versus time as a function of geometrical parameters of the fruit as well as dehydration process conditions, such as 
the base radius and height of cone-shaped fruit, water diffusion coefficient in fruit, initial water concentration of fruit, and water concentration in hypertonic solution. The effect of the above mentioned parameters on dehydration kinetics of cone-shaped fruits was investigated using the presented model. The results showed that the water diffusion coefficient and the initial water concentration of fruit have direct effects on the dehydration rate and also inverse effect on the dehydration duration. On the other hand, the geometrical parameters of fruit (i.e. base radius and height) and water concentration in hypertonic solution showed direct effect on the dehydration duration as well as inverse effect on the dehydration rate. Using the developed model one can predict the osmotic dehydration kinetics for cone-shaped fruits and vegetables without performing experiments and also can design optimum conditions for osmotic dehydration process. It should be noted that the presented model can be recognized as an approximated tool to predict the osmotic dehydration process of normal cone-shaped fruits and vegetables, such as strawberries, where the values of the height and base radius of fruit are comparable. But for the cone-shaped fruits and vegetables having the high ratio of height to base radius (b>>a), e.g. carrot and pepper, where the mass transfer can be assumed one dimensional (in radial direction), the proposed model may give good approximation for osmotic dehydration kinetics. However, experimental study is suggested for the validation of the developed model in this work.

\section{References}

Alam MS, Singh A. 2010. Optimization of osmotic dehydration process of Aonla fruit in salt solution. International Journal of Food Engineering. 6: 1-22.

Bui HT, Makhlouf J, Ratti C. 2009. Osmotic dehydration of tomato in sucrose solutions: Fick's law classical modeling. Journal of Food Science. 74: E250-E258.

Chenlo F, Moreira R, Fernandez-Herrero C, Vazquez G. 2006. Experimental results and modeling of the osmotic dehydration kinetics of chestnut with glucose solutions. Journal of Food Engineering. 74: 324-334.

Garcia CC, Mauro MA, Kimura M. 2007. Kinetics of osmotic dehydration and air-drying of pumpkins (Cucurbita moschata). Journal of Food Engineering. 82: 284-291.
Garcia-Segovia P, Mognetti C, Andres-Bello A, Martinez-Monzo J. 2010. Osmotic dehydration of Aloe vera (Aloe barbadensis Miller). Journal of Food Engineering. 97: 154-160.

Ispir A, Togru IT. 2009. Osmotic dehydration of apricot: Kinetics and the effect of process parameters. Chemical Engineering Research and Design. 87: 166-180.

Kaymak-Ertekin F, Sultanoglu M. 2000. Modelling of mass transfer during osmotic dehydration of apples. Journal of Food Engineering. 46: 243-250.

Moreira R, Chenlo F, Torres MD, Vazquez G. 2007. Effect of stirring in the osmotic dehydration of chestnut using glycerol solutions. LWT-Food Science and Technology. 40: 1507-1514.

Ohnishio Sh., Miyawaki O. 2005. Osmotic dehydrofreezing for protection of rheological properties of agricultural products from freezing-injury. Food Science and Technology Research. 22: $52-58$.

Pisalkar PS, Jain NK, Pathare PB, Murumkar RP, Revaskar VA. 2014. Osmotic dehydration of aloe vera cubes and selection of suitable drying model. International Food Research Journal. 21: 373-378.

Segu L, Fito PJ, Albors A, Fito P. 2006. Mass transfer phenomena during the osmotic dehydration of apple isolated protoplasts (Malus domestica var. Fuji). Journal of Food Engineering. 77: 179-187.

Silva KS, Fernandes MA, Mauro MA. 2014. Osmotic dehydration of pineapple with impregnation of sucrose, calcium, and ascorbic acid. Food and Bioprocess Technology. 7: 385-397.

Simpson R, Ramirez C, Birchmeier V, Almonacid A, Moreno J, Nunez H, Jaques A. 2015. Diffusion mechanisms during the osmotic dehydration of Granny Smith apples subjected to a moderate electric field. Journal of Food Engineering. 166: 204211.

Sirousazar M, Mohammadi-Doust A, Achachlouei BF. 2009. Mathematical investigation of the effects of slicing on the osmotic dehydration of sphere and cylinder shaped fruits. Czech Journal of Food Sciences. 27: 95-101.

Sutar PP, Gupta DK. 2007. Mathematical modeling of mass transfer in osmotic dehydration of onion slices. Journal of Food Engineering. 78: 90-97.

Vega-Mercado H, Gongora-Nieto MM, Barbosa-Canovas GV. 2001. Advances in dehydration of foods. Journal of Food Engineering. 49: 271-289.

Zita NEB, Emmanuel AN, Patrice K, Ismael D, Benjamin Y. 2009. Modelling of osmotic dehydration of Mango (Mangifera Indica) by recurrent artificial neural network and experimental design. Research Journal of Agriculture and Biological Sciences. 5: 754-761. 